\title{
Unitary GABAergic volume transmission from individual interneurons to astrocytes in the cerebral cortex
}

\author{
Márton Rózsa ${ }^{1} \cdot$ Judith Baka $^{1} \cdot$ Sándor Bordé $^{1} \cdot$ Balázs Rózsa $^{2}$ - Gergely Katona ${ }^{2}$. \\ Gábor Tamás ${ }^{1}$
}

Received: 5 October 2015/ Accepted: 27 November 2015

(C) Springer-Verlag Berlin Heidelberg 2015

\begin{abstract}
Communication between individual GABAergic cells and their target neurons is mediated by synapses and, in the case of neurogliaform cells (NGFCs), by unitary volume transmission. Effects of non-synaptic volume transmission might involve nonneuronal targets, and astrocytes not receiving GABAergic synapses but expressing GABA receptors are suitable for evaluating this hypothesis. Testing several cortical interneuron types in slices of the rat cerebral cortex, we show selective unitary transmission from NGFCs to astrocytes with an early, $\mathrm{GABA}_{\mathrm{A}}$ receptor and GABA transporter-mediated component and a late component that results from the activation of GABA transporters and neuronal $\mathrm{GABA}_{\mathrm{B}}$ receptors. We could not detect $\mathrm{Ca}^{2+}$ influx in astrocytes associated with unitary GABAergic responses. Our experiments identify a presynaptic cell-type-specific, GABA-mediated communication pathway from individual neurons to astrocytes, assigning a role for unitary volume transmission in the control of ionic and neurotransmitter homeostasis.
\end{abstract}

Keywords Interneuron $\cdot \mathrm{GABA}_{\mathrm{A}} \cdot \mathrm{GABA}_{\mathrm{B}} \cdot$ Neocortex

Gábor Tamás

gtamas@bio.u-szeged.hu

1 MTA-SZTE Research Group for Cortical Microcircuits, Department of Anatomy, Physiology and Neuroscience, University of Szeged, Közép fasor 52, Szeged 6726, Hungary

2 Two-Photon Imaging Center, Institute of Experimental Medicine, Hungarian Academy of Sciences, Budapest 1083, Hungary

\section{Introduction}

According to the classical interpretation, the output of individual GABAergic cells in the cerebral cortex is mediated via synapses operating in a spatially and temporally highly regulated manner (Miles and Wong 1984; Freund and Buzsáki 1996; Thomson et al. 2002; Pouille and Scanziani 2004; Markram et al. 2004; Klausberger and Somogyi 2008). Apart from targeting receptors located in the postsynaptic density, synaptically released GABA diffuses out of the synaptic cleft to reach extrasynaptic receptors producing tonic inhibition (Otis et al. 1991; Barbour and Häusser 1997; Farrant and Nusser 2005). Neurogliaform interneurons (NGFCs) were suggested to specialize in acting on GABA receptors on compartments of the neuronal surface which do not receive synaptic junctions through a unitary form of volume transmission (Vizi et al. 2004; Agnati et al. 2006; Oláh et al. 2009; Capogna 2011; Chittajallu et al. 2013). In the same vein, neurogliaform interneurons might act on non-neuronal elements of the surrounding cortical tissue without establishing synaptic contacts.

Direct synaptic junctions from neurons to glial cells appear to be restricted to connections linking neurons and NG2-expressing glial cells (Bergles et al. 2000; Lin and Bergles 2004) in the cerebral cortex. In spite of the apparent absence of synapses on other glial cells, functional, depolarizing GABAergic responses are characteristic of glia (Kettenmann et al. 1984), and the presence of various GABA receptors and transporters is widely established (Porter and McCarthy 1997; Eulenburg and Gomeza 2010). Accordingly, potentially non-synaptic GABAergic interactions between neurons and several types of glia were suggested by exogenously applied agonists (Kettenmann et al. 1984; Meier et al. 2008) and prolonged, high- 
frequency stimulation of GABAergic interneurons (Kaila et al. 1997; Kang et al. 1998; Egawa et al. 2013) or stimulation of the mossy fiber pathway (Haustein et al. 2014), but physiological activation of GABA receptors on astrocytes is not clearly shown (Velez-Fort et al. 2012; Losi et al. 2014).

\section{Materials and methods}

\section{Slice preparation}

Experiments were conducted according to the guidelines of the University of Szeged Animal Care and Use Committee. Astrocytes are considered mature after postnatal day (P)20 (Bushong et al. 2004; Zhou 2005; Cahoy et al. 2008; Sun et al. 2013); thus, we used young adult ((P)25-46, (P)37.4 \pm 4.5 ) male Wistar rats for the electrophysiological and imaging experiments. Animals were anaesthetized by inhalation of halothane, and following decapitation, (320 $\mu \mathrm{m}$ thick) coronal slices were prepared from their somatosensory cortex. Slices were incubated at room temperature for $1 \mathrm{~h}$ in a solution composed of (in $\mathrm{mM}$ ) 130 $\mathrm{NaCl}, 4.5 \mathrm{KCl}, 1 \mathrm{NaH}_{2} \mathrm{PO}_{4}, 24 \mathrm{NaHCO}_{3}, 1 \mathrm{CaCl}_{2}, 3$ $\mathrm{MgSO}_{4}, 10 \mathrm{D}(+)$-glucose, gassed with $95 \% \mathrm{O}_{2}$, and $5 \%$ $\mathrm{CO}_{2}$. The solution used for recordings had the same composition except that the concentrations of $\mathrm{CaCl}_{2}$ and $\mathrm{MgSO}_{4}$ were $3 \mathrm{mM}$ and $1.5 \mathrm{mM}$, respectively. Given that neurons and mature astrocytes have similar intracellular ionic milieux (Ballanyi et al. 1987; Ma et al. 2012), we used the same intracellular solution for both. The micropipettes (3-6 MOhm) were filled with (in $\mathrm{mM}$ ) $126 \mathrm{~K}$ gluconate, 4 KCl, 4 ATP-Mg, 0.3 GTP-Na, 10 HEPES, 10 kreatin phosphate ( $\mathrm{pH} 7.25 ; 300$ mOsm). For neurons, we added $8 \mathrm{mM}$ biocytin, whereas for astrocytes, in order to avoid extensive dye coupling, we used $0.3 \mathrm{mM}$ biotinylated dextran (BDA). For some experiments, $1 \mathrm{mM}$ GDP$\beta-\mathrm{S}$ was also added as described in the text.

\section{Electrophysiology and pharmacology}

Somatic whole-cell recordings were obtained at $\sim 36{ }^{\circ} \mathrm{C}$ from simultaneously recorded doublets of interneurons and astrocytes visualized by infrared differential interference contrast videomicroscopy (Olympus BX microscopes equipped with oblique illumination, Luigs \& Neumann Infrapatch setup and HEKA EPC 10 USB patch-clamp amplifier). Signals were filtered at $5 \mathrm{kHz}$, digitized at $15 \mathrm{kHz}$, and analyzed with Patchmaster (HEKA) and MATLAB software (The MathWorks). Presynaptic interneurons were stimulated to elicit action potentials with brief (1-20 ms) suprathreshold pulses in current clamp mode at intervals $>90 \mathrm{~s}$. The astrocytes were recorded in voltage clamp mode to achieve better signal-to-noise ratio. The astrocytes were held at their resting membrane potential which was determined in unclamped cells without added holding current. The average astrocytic membrane potential was $-90.2 \pm 3.9 \mathrm{mV}$, close to the calculated equilibrium potential $(-89 \mathrm{mV})$ for potassium ions. Astrocytes cannot be perfectly clamped from the somata due to their elaborate processes and exceptionally low input resistance; thus, the recorded currents might reflect the activity taking place relatively close to the tip of the recording electrode. All the stated membrane potential values are corrected with a calculated $(-13.3 \mathrm{mV})$ liquid junction potential.

The astrocytic access resistance $\left(R_{\mathrm{A}}\right)$ was measured in voltage clamp mode with a $100-\mathrm{ms}-$ long $-5 \mathrm{mV}$ big voltage step by measuring the initial peak current right after the voltage step. The astrocytic input resistance $\left(R_{\mathrm{In}}\right)$ estimation consisted of two steps. First, we determined the sum of the input and access resistance $\left(R_{\mathrm{SUM}}=R_{\mathrm{A}}+R_{\mathrm{In}}\right)$ in current clamp mode (without bridge balancing) by measuring the steady-state voltage deflection in response to a current step ( $800 \mathrm{~ms},-200 \mathrm{pA}$ ). Next, we measured the access resistance in voltage clamp mode in the abovementioned way. We estimated the input resistance to be the difference in the two measured resistance values (i.e., $\left.R_{\mathrm{SUM}}-R_{\mathrm{A}}=R_{\mathrm{In}}\right)$.

All the pharmacological experiments were carried out with NGFC-astrocyte pairs using currents elicited by single action potentials. Experiments were stopped if the astrocytic access resistance exceeded $25 \mathrm{MOhms}$ or changed more than $25 \%$. CGP35348 was applied in $40 \mu \mathrm{M}$ concentration and purchased from Tocris, gabazine; NO711 and GDP- $\beta$-S were applied in $5,100 \mu \mathrm{M}$, and $1 \mathrm{mM}$, respectively, and were purchased from Sigma. Oregon Green BAPTA-1 and Alexa Fluor 594 were applied in $120 \mu \mathrm{M}$ abd $20-50 \mu \mathrm{M}$ and were purchased from Invitrogen.

\section{Two-photon calcium imaging}

Astrocytes were filled with two fluorescent dyes: a $\mathrm{Ca}^{2+}$ insensitive fluorophore (Alexa Fluor 594, 20-50 $\mu \mathrm{M}$ ), and a $\mathrm{Ca}^{2+}$-sensitive fluorophore (Oregon Green BAPTA-1, $120 \mu \mathrm{M})$. Red fluorescence was used to identify glial processes and cancel movement artefacts. Neurons were occasionally filled with Alexa Fluor $594(20-50 \mu \mathrm{M})$. Imaging was performed with a Femto3D-AO (Femtonics Ltd.) acousto-optic laser-scanning microscope (Katona et al. 2012) driven by a MaiTai femtosecond pulsing laser (MaiTai, SpectraPhysics) tuned to $850 \mathrm{~nm}$. We used a 60X Olympus $(\mathrm{NA}=0.9)$ objective in order to resolve small processes. Both reflected and transmitted fluorescent lights were collected (through an oil-immersion condenser, 
Olympus; NA $=1.4$ ). 150-500 ROIs were automatically selected in an approximately $100 \times 100 \times 50 \mu \mathrm{m}$ volume based on previously obtained Z-stacks. Image acquisition was controlled by custom-made software written in MATLAB (MES, Femtonics Ltd.). In the 60- to 120-s-long imaging sessions, the sampling frequency on each ROI ranged from 40 to $120 \mathrm{~Hz}$, and $3-8 \mathrm{~mW}$ laser power reached the slice during imaging.

\section{Post hoc anatomical analysis}

The electrophysiologically recorded cells were filled with biocytin or biotinylated dextran, which allowed post hoc anatomical analysis of the tested connections. Anatomical recovery rates were lower than expected due to the lengthy recordings using very low presynaptic activation frequencies. We kept recording NGFC-astrocyte pairs in each recording paradigm until we had at least two NGFCs anatomically recovered. The NGFCs were identified by their relatively small somata, dense and local axonal arborizations, and their thin axons with a large number of boutons. The non-NGFCs had relatively large somata and sparse axonal arborizations, and their axons usually reached other cortical layers as well. Identified interneuronal axon collaterals crossing the territory of the intracellularly filled astrocyte were reconstructed in 3D (Neurolucida, MicroBrightfield) for further analysis.

\section{Analysis and statistics}

The analysis and statistics of electrophysiology and imaging data were performed in MATLAB, with the help of Statistics Toolbox, Image Processing Toolbox, and custom written scripts. For the measurement of early and late components of NGFC-evoked astrocyte currents, the traces were downsampled to $1 \mathrm{kHz}$ and a moving average was applied to the traces ( $5 \mathrm{~ms}$ for the early and $50 \mathrm{~ms}$ for the late component); then, the maximal current difference was measured in the first $35 \mathrm{~ms}$ and in the first $550 \mathrm{~ms}$ after the action potential for the two components, respectively. This measurement was also applied prior to the action potential, where we anticipated no elicited current. We stated measurable elicited current only if the two sets of amplitudes (measured amplitudes before and after the action potential) significantly differed according to Wilcoxon signed-rank test $(p<0.05)$. At each connection, the average of 5-30 $(11.04 \pm 5.05)$ traces was used for further analysis. We applied a Gaussian filter ( $\sigma=100 \mathrm{~ms})$ to the two-photon calcium imaging traces, and a calcium event was detected when the peak amplitude of the event exceeded $3 \mathrm{SD}$ of the baseline fluorescence. The average frequencies and amplitudes of the calcium events were measured in a 1-s sliding time window. Data were statistically tested by parametric tests (paired $t$ test or two-sample $t$ test) if they passed the Lilliefors test for normal distribution, and nonparametric tests (Wilcoxon signed-rank test or MannWhitney $U$ test) were applied in all other cases. Linear correlations were tested using Pearson's linear correlation coefficient. Error bars and shaded areas show standard deviation.

\section{Results}

\section{Cell-type-specific coupling from interneurons to astrocytes}

Following reports indicating that certain neocortical interneurons might specialize in non-synaptic volume transmission (Oláh et al. 2009; Craig and McBain 2014), we performed dual whole-cell patch-clamp recordings of closely spaced $(<130 \mu \mathrm{m})$ interneuron-astrocyte cell pairs ( $n=209$ ), testing the output of $n=164$ neurons in layer 1 of the rat somatosensory cortex (Fig. 1). All the glial cells recorded had features typical of mature astrocytes (Zhou 2005; Mishima and Hirase 2010) having highly negative membrane potential $(-90.2 \pm 3.9 \mathrm{mV})$ and low input resistance (estimated value: $1.05 \pm 3.94 \mathrm{M} \Omega$ ). The morphology of the glial cell was recovered in $n=54$ paired recordings and identified as that of an astrocyte in all cases (Fig. 1). Classification of the recorded interneurons could be based on anatomical recovery in $n=66$ pairs, of which we identified $n=53$ NGFCs and $n=13$ non-NGFCs. To extend the classification to interneurons with no anatomical recovery, we developed a cell sorting method based on electrophysiological parameters of anatomically identified NGFCs and non-NGFCs by using backward search (Li et al. 2008) and scatter separability criteria (Dy and Brodley 2004). This identified the best feature combination for distinguishing between the two groups of cells, and then, we applied Gaussian mixture model (GMM) clustering (McLachlan and Peel 2000) $(p<0.05)$. This allowed us to sort the remaining $n=98$ neurons with no anatomical recovery into neurogliaform (NGFC, $n=61$ ), nonneurogliaform (non-NGFC, $n=37$ ) or unidentified groups $(n=28$, not shown).

The analysis of the responses of astrocytes to single action potentials triggered in interneurons revealed that nonNGFCs induced no detectable current. In contrast, single action potentials in NGFCs evoked measurable $(p<0.05$, Wilcoxon signed-rank test) inward currents in $63.1 \%$ of simultaneously recorded astrocytes with amplitudes of $2.48 \pm 1.78 \mathrm{pA}$ ( $n=82$ of the 130 pairs tested). These data suggest a cell-type-specific coupling from interneurons to astrocytes. The NGFC-elicited inward currents consisted of two components, an early component with short $(1.6 \mathrm{~ms})$ 


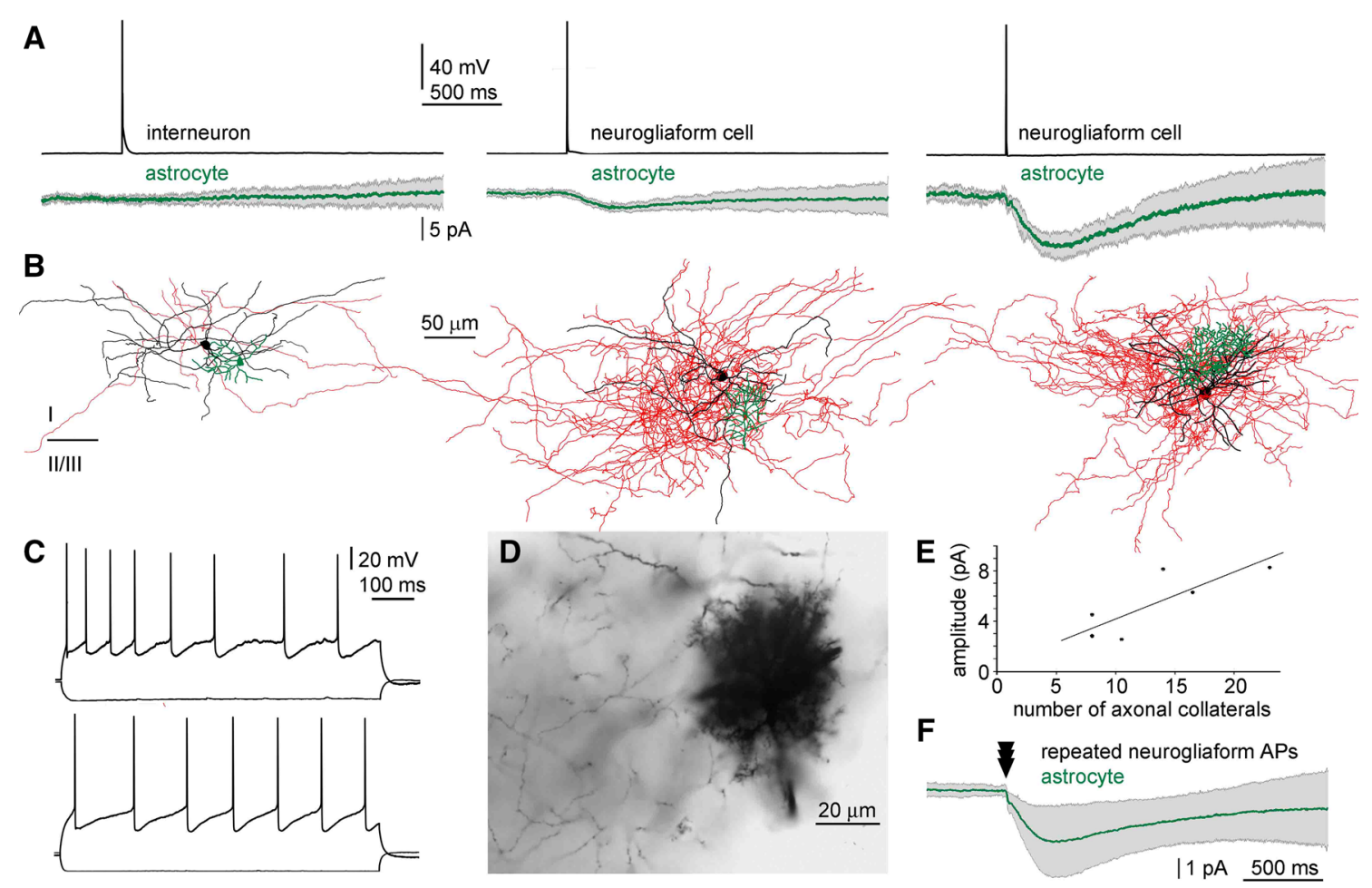

Fig. 1 Cell-type-specific effect of GABAergic interneurons on astrocytes. a Single action potentials in layer 1 non-NGFCs (black, left panel) had no detectable effect on simultaneously recorded astrocytes (green average with gray SD). In contrast, unitary spikes in NGFCs elicited short latency, long-lasting inward currents in astrocytes in layer 1 (middle and right panel) b anatomical reconstructions of the interneuron-astrocyte pairs shown on a (interneuron somata, black, interneuron axons, red, astrocytic processes, green). Note the axon density around each astrocyte. c Top, Firing pattern of

latency, and a late component with an onset around $35 \mathrm{~ms}$ after the action potential. The early component had an average amplitude of $0.68 \pm 0.45 \mathrm{pA}$ and average $10-90 \%$ rise time of $12.9 \pm 6.9 \mathrm{~ms}$. The late component had an average amplitude of $1.96 \pm 1.89 \mathrm{pA}$ and average 10-90\% rise time of $176.6 \pm 87.8 \mathrm{~ms}(n=82)$. Recordings from interneurons performed in vivo showed sporadic single spikes or brief burst of activity (Gentet et al. 2010); thus, we repeated the experiments above, eliciting a rapid series of action potentials in the interneurons [ $2-6$ action potentials at 44-522, $255 \pm 72 \mathrm{~Hz} \quad$ (minimum-maximum, mean $\pm \mathrm{SD})]$. In line with the single spike data, the effect of NGFCs $(n=28)$ was readily detectable with similar kinetics and amplitudes sublinearly increasing with the number of action potentials (Fig. 1f), while 24 out of 27 tested nonNGFCs remained completely ineffective. The $n=3$ nonNGFCs ( $n=1$ with anatomical recovery) required a minimum of three action potentials at $262.2 \pm 57.4 \mathrm{~Hz}$ in order to have a measurable effect on astrocytes, but these currents were kinetically different from one another and also from the the layer 1 non-NGFC shown on the left of $\mathbf{a}$, b. Bottom, Firing pattern of the NGFC shown in the center of $\mathbf{a}, \mathbf{b}$. d Light micrograph of the astrocytic field at the edge of the neurogliaform axon shown on the middle of $\mathbf{b}$. e Correlations between peak amplitudes of astrocytic inward currents and the number of axonal collaterals crossing the territory of astrocytes filled with BDA to prevent dye coupling (linear correlation, $p=0.046$ ). f Multiple action potentials in NGFCs elicited astrocytic responses with similar kinetics to single action potential triggered responses

NGFC-induced currents, rendering statistically reliable analysis impossible.

All interneurons with anatomical recovery triggering a detectable effect showed the very dense axonal arborization typical of NGFCs. By contrast, non-NGFCs, whichfollowing single spikes-had no effect on astrocytes, displayed relatively sparse axonal arborizations. We reconstructed the interacting NGFCs and the spatial boundary of astrocytes filled with biotinylated dextran $(n=6)$ in three dimensions. When counting the number of neurogliaform axonal collaterals crossing the field of the astrocyte, we found linear correlation with the amplitude of the inward current measured on the astrocyte $(r=0.818, p=0.046$, $n=6$, Fig. 1e), which suggested that the density of the interneuron output contributes to the effectiveness of connections. Moreover, a correlation between the amplitude of astrocytic inward current and the distance between the tips of the recording electrodes simultaneously placed on the somata of NGFCs and astrocytes was also revealed $(r=-0.306 p=0.03, n=82)$, potentially due to the 
decrease in axonal density toward the edge of the axonal cloud.

\section{The astrocytic inward current consists of an early direct and a late indirect component}

The biphasic time course of astrocytic responses to NGFC activation detailed above indicates that potentially complex mechanisms form the basis of these cell-type-specific pathways. Astrocytes are known to participate in potassium clearance from the extracellular space (Amzica et al. 2002; Kofuji and Newman 2004); thus, we applied $\mathrm{BaCl}_{2}$, a concentration-dependent blocker of GIRK and KIR channels (Hibino et al. 2010) in the bath in search for potential $\mathrm{K}^{+}$currents (Fig. 2). These experiments revealed an early, barium-insensitive and a late, barium-sensitive component of the astrocytic inward current induced by single action potentials in NGFCs. Applied at low concentrations (5-10 $\mu \mathrm{M}), \mathrm{BaCl}_{2}$ significantly reduced the late component probably by acting on GIRK channels (from $4.35 \pm 1.71$ to $1.59 \pm 0.82 \mathrm{pA}, p=0.004, n=5$ ) without affecting the early component. High concentration of $\mathrm{BaCl}_{2}(100 \mu \mathrm{M})$ abolished the late component (from $1.80 \pm 1.32$ to $0.08 \pm 0.18 \mathrm{pA}, p=0.0031, n=7)$ and increased the early component (from $1.17 \pm 0.57$ to $2.71 \pm 1.26 \mathrm{pA}$, $p=0.009, n=7)$ most likely by broadening action potentials (from $0.77 \pm 0.12 \mathrm{~ms}$ to $0.85 \pm 0.13 \mathrm{~ms}$, $p=0.023, n=7)$ and increasing the presynaptic neurotransmitter release or by increasing the input resistance and decreasing the attenuation of the signal due to KIR channel blockade (Williams and Mitchell 2008; Hibino et al. 2010; Ma et al. 2014).

Following pioneering reports showing that $\mathrm{GABA}_{\mathrm{A}}$ receptors depolarize astrocytes (Kettenmann et al. 1984) and given that NGFCs release GABA (Tamas 2003), we tested whether GABAergic transmission contributes to single-cell-evoked currents. Bath application of gabazine $(5 \mu \mathrm{M}), \mathrm{GABA}_{\mathrm{A}}$ receptor blocker, significantly reduced both the early potassium-independent and the late potassium-dependent inward current (from $1.28 \pm 0.62$ to $1.01 \pm 0.51 \mathrm{pA}, p=0.024, n=5$ for the early component and from $1.76 \pm 1.52$ to $0.88 \pm 0.61 \mathrm{pA}, p=0.032$, $n=5$ for the late component). The biphasic effect of $\mathrm{GABA}_{\mathrm{A}}$ receptor blockade reflects the direct $\mathrm{GABA}_{\mathrm{A}}$ receptor activation in the early component and the subsequent increase in extracellular $\mathrm{K}^{+}$ions due to the neuronal potassium-dependent chloride extrusion (Kaila et al. 1997; Viitanen et al. 2010) in the late component. Besides
A

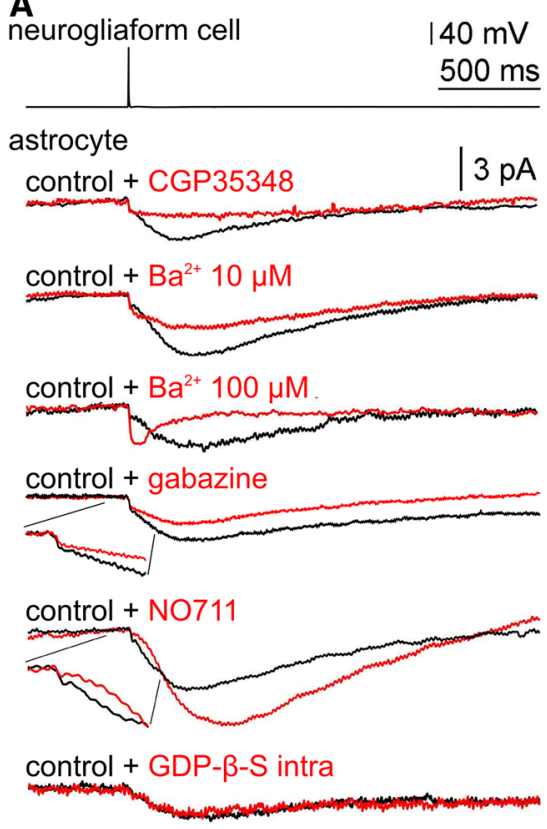

Fig. 2 Neurogliaform cell-triggered, unitary GABAergic astrocytic currents are mediated by $\mathrm{GABA}_{\mathrm{A}}$ receptors, GABA transporters, and $\mathrm{GABA}_{\mathrm{B}}$ receptors. a Top, testing unitary NGFC-triggered astrocytic response to extracellularly delivered $\mathrm{GABA}_{\mathrm{B}}$ receptor antagonist CGP35348, potassium channel blocker $\mathrm{Ba}^{2+}, \mathrm{GABA}_{\mathrm{A}}$ receptor antagonist gabazine, GAT-1 GABA transporter blocker NO711, and to intracellularly applied G-protein-coupled receptor antagonist GDPbeta-sulfate (GDPBS). b Summary of population data measured at the

\section{B}
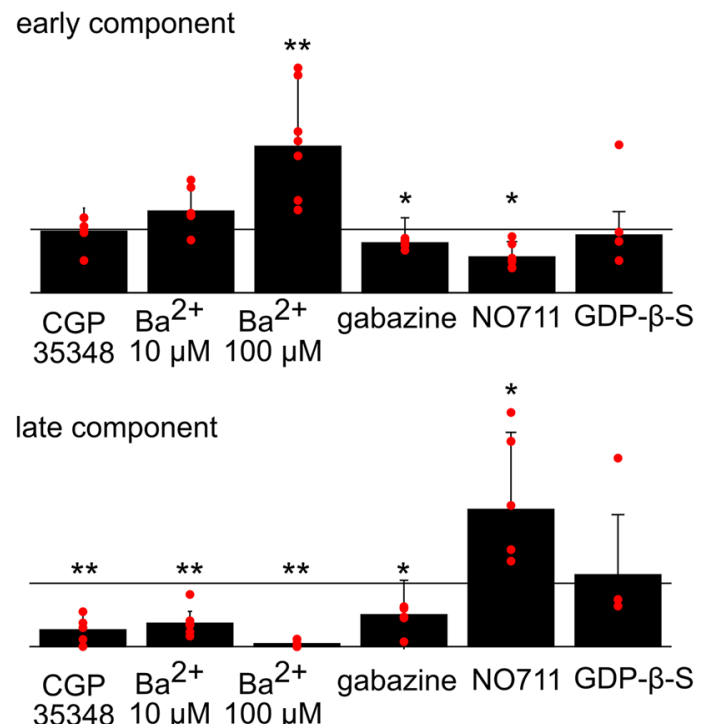

early (top) and late (bottom) component of astrocytic responses. Data are normalized to amplitudes measured before drug application (horizontal line, $100 \%$ ). Amplitudes of the early and late components were measured as maximal changes from baseline values in time windows of $0-35$ and $35-550 \mathrm{~ms}$ following the action potential, respectively. The displayed traces are the averages of all recordings. Asterisks indicate significant difference $(* p<0.05 ; * * p<0.01)$ 
$\mathrm{GABA}_{\mathrm{A}}$ receptors, astrocytes also express GABA transporters to remove the neurotransmitter from the extracellular space, which is accompanied by an inward $\mathrm{Na}^{+}$ current (Doengi et al. 2009; Eulenburg and Gomeza 2010). Bath application of the GABA reuptake inhibitor (GAT1 inhibitor) NO711 $(100 \mu \mathrm{M})$ alone reduced the astrocytic early component (from $1.21 \pm 0.51$ to $0.68 \pm 0.29 \mathrm{pA}$, $p=0.023, n=6$ ). These results show that GABA released from single neurogliaform axons non-synaptically acts on astrocytic $\mathrm{GABA}_{\mathrm{A}}$ receptors, inducing chloride and probably bicarbonate ion efflux and, furthermore, confirm the contribution of potassium-dependent chloride and sodiumdependent GABA transport to neurogliaform-to-astrocyte signaling. In addition to the astrocytic early component, NO711 significantly increased the amplitude of the astrocytic late component (from $3.27 \pm 2.18$ to $7.08 \pm 3.98$ $\mathrm{pA}, p=0.031, n=6$ ) and prolonged the $10-90 \%$ rise time (from $203 \pm 16 \mathrm{~ms}$ to $310 \pm 49 \mathrm{~ms}, p=0.0004$ ).

The astrocytic late component was also sensitive to the selective $\mathrm{GABA}_{\mathrm{B}}$ receptor antagonist CGP35348 $(40 \mu \mathrm{M})$, which reduced the late component (from $1.77 \pm 0.99$ to $0.45 \pm 0.42 \mathrm{pA}, p<0.01, n=6$ ) reminiscent of the $\mathrm{BaCl}_{2}$ application. Thus, the late component appears to be mediated by $\mathrm{GABA}_{\mathrm{B}}$ receptors coupled to $\mathrm{K}^{+}$channels, and, as such, it is amplified by GABA transporter blockade. However, given the high-resolution immunohistochemical and in situ hybridization results of independent reports, which failed to detect $\mathrm{GABA}_{\mathrm{B}}$ receptors on mature astrocytes (Kaupmann et al. 1997; López-Bendito et al. 2004; Martin et al. 2004; Fritschy et al. 2004; Luján and Shigemoto 2006), the $\mathrm{GABA}_{\mathrm{B}}$ receptors responsible for the recorded current might not reside on the astrocytes. So, we tried to block $\mathrm{GABA}_{\mathrm{B}}$ receptors in the astrocytes intracellularly, using the G-protein blocker GDP- $\beta-\mathrm{S}(1 \mathrm{mM})$, but this resulted in no significant changes (Fig. 2). As a control, the slow $\mathrm{GABA}_{\mathrm{B}}$ component of unitary neurogliaform-to-pyramidal cell IPSPs was abolished with intracellular application of GDP- $\beta$-S in pyramidal cells under the same conditions $(n=3$, not shown). These results suggest that the activation of neuronal $\mathrm{GABA}_{\mathrm{B}}$ receptors leads to potassium efflux from neurons and a subsequent passive inward potassium current in astrocytes.

\section{Physiological release of GABA does not elicit detectable calcium events in surrounding astrocytes}

Astrocytes exhibit intense local $\mathrm{Ca}^{2+}$ events (Grosche et al. 1999; Di Castro et al. 2011; Volterra et al. 2014), the dynamics of which were suggested to be modulated by GABAergic signaling through several mechanisms. The activation of $\mathrm{GABA}_{\mathrm{A}}$ receptors was reported to elicit $\mathrm{Ca}^{2+}$ signals in astrocytes through membrane depolarization and subsequent voltage-dependent $\mathrm{Ca}^{2+}$ channel recruitment
(Meier et al. 2008), but the effectiveness of endogenously released GABA in astroglial $\mathrm{Ca}^{2+}$ dynamics is yet to be established (Velez-Fort et al. 2012). Increased $\mathrm{Ca}^{2+}$ dynamics following astrocytic $\mathrm{GABA}_{\mathrm{B}}$ receptor activation has repeatedly been observed (Nilsson et al. 1993; Kang et al. 1998; Serrano 2006); however, $\mathrm{GABA}_{\mathrm{B}}$ receptormediated $\mathrm{Ca}^{2+}$ events could only be detected in cultured astrocytes, which are known to be distinct from mature cells (Cahoy et al. 2008), or in young animals (Meier et al. 2008) consistent with the transient expression of $\mathrm{GABA}_{B}$ receptors in astrocytes (López-Bendito et al. 2004; Fritschy et al. 2004; Luján and Shigemoto 2006). To reveal the diverse $\mathrm{Ca}^{2+}$ signals in both astrocytic somata and processes (Volterra et al. 2014), we intracellularly filled (Di Castro et al. 2011) single astrocytes in the close vicinity $(<70 \mu \mathrm{m})$ of identified NGFCs with the calcium indicator OGB-1 $(120 \mu \mathrm{M})$ and a calcium-insensitive structure dye Alexa Fluor $594(40 \mu \mathrm{M})$. Then, we randomly selected 100-300 regions of interest on the processes of the intracellularly filled as well as of the neighboring astrocytes dye coupled through gap junctions (Fig. 3). We readily detected spontaneous $\mathrm{Ca}^{2+}$ events of variable amplitude and duration. However, we could not detect any increase in the amplitude or frequency of these events following single action potentials in NGFCs, although it might have been anticipated on the basis of previous reports (Nilsson et al. 1993; Kang et al. 1998; Serrano 2006; Meier et al. 2008). This suggests that the magnitude of unitary evoked measurable inward currents is not sufficient to depolarize the membrane for the recruitment of voltage-gated $\mathrm{Ca}^{2+}$ channels, and furthermore, it also indicates the absence of $\mathrm{GABA}_{\mathrm{B}}$ receptor activation-dependent $\mathrm{Ca}^{2+}$ signaling.

\section{Discussion}

Non-synaptic or volume transmission acts ubiquitously on all-neuronal and non-neuronal-target elements expressing receptors for the released transmitter (Vizi and Kiss 1998). Neurogliaform cells were suggested to operate by flooding the axonal arborization with GABA, resulting in a single-cell-driven volume transmission (Oláh et al. 2009). The results presented here extend this concept and identify a cell-type-specific route for interneuron to astrocyte signaling in addition to the conventional GABAergic output toward neurons. Neurogliaform cell to astrocyte communication has several GABAergic elements. The early component has a contribution of currents mediated by $\mathrm{GABA}_{\mathrm{A}}$ receptors and GABA transporters, and its short latency indicates a direct communication pathway from NGFCs to astrocytes. We cannot rule out the possibility of electrotonic coupling between NGFCs and astrocytes based on these data; however, the latency of $1.6 \mathrm{~ms}$ strongly 
A

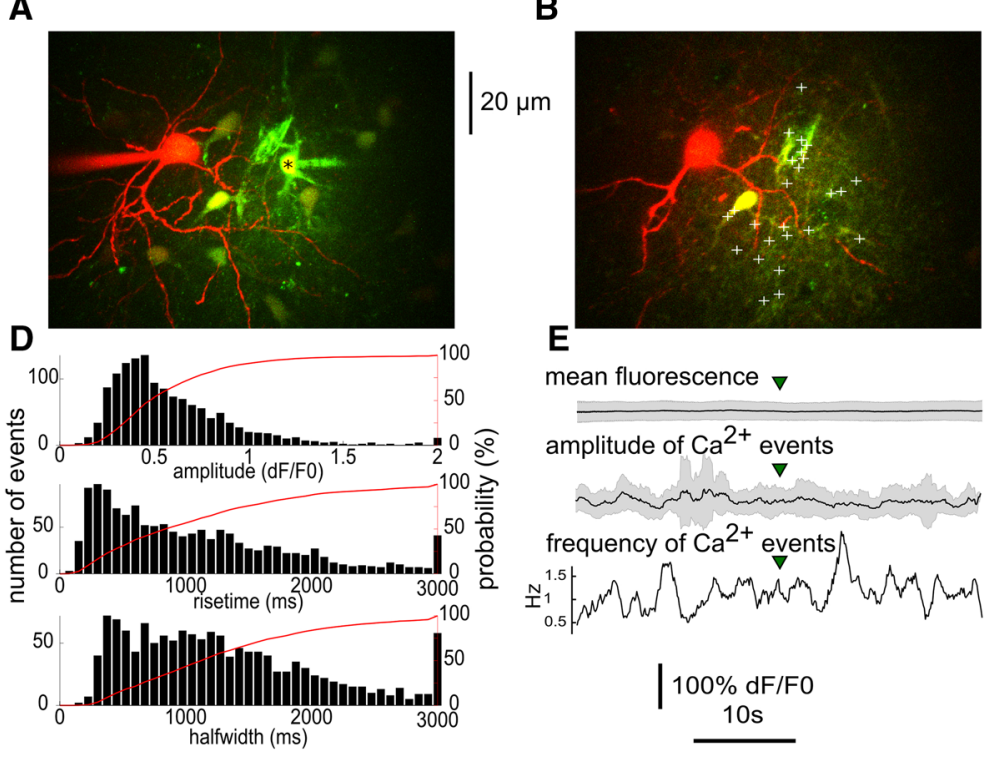

C

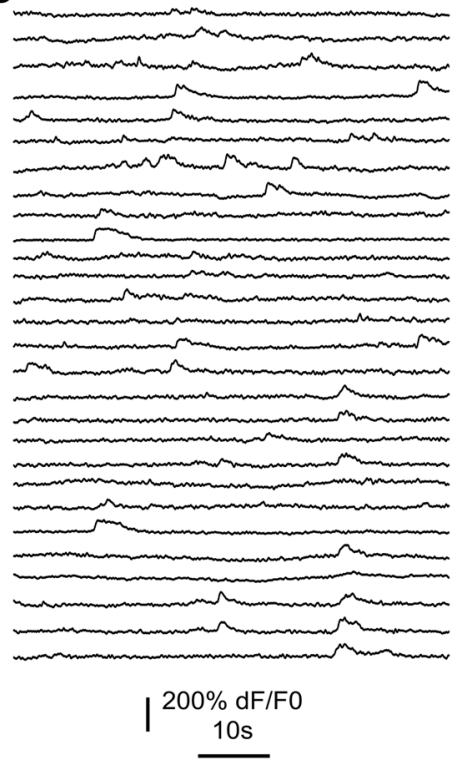

Fig. 3 Dynamics of calcium transients in astrocytes following unitary activation of nearby NGFCs. a Confocal Z-stack image showing a simultaneously whole-cell recorded NGFC (red) and an astrocyte (green). Several neighboring astrocytes are dye coupled to the recorded one (asterix) through gap junctions. b A representative optical plane showing sites (white crosses) for detecting calcium transients in astrocytic processes. $\mathbf{c}$ Examples of $\mathrm{Ca}^{2+}$ activity in the

suggests that there is no gap junctional current in the early component (Simon et al. 2005). The second, indirect GABAergic pathway involves the activity of chloride transporters and $\mathrm{GABA}_{\mathrm{B}}$ receptors presumably located on neuronal elements of the circuit, and the resulting extracellular accumulation of $\mathrm{K}^{+}$is taken up by astrocytes as the late component. The net result of this cascade of events is the transport of $\mathrm{K}^{+}$through the extracellular space and a transient rise in $\mathrm{Cl}^{-}$and/or bicarbonate in the extracellular space. Both of these factors contribute to the suppression of neuronal excitability by membrane hyperpolarization and by maintaining the driving force of GABAergic synapses, respectively. More importantly, these mechanisms are activated while NGFCs act on $\mathrm{GABA}_{\mathrm{A}}$ receptors on dendritic compartments and $\mathrm{GABA}_{\mathrm{B}}$ receptors on presynaptic terminals of neighboring neurons providing simultaneous means for multiple inhibition (Oláh et al. 2009; Capogna 2011; Chittajallu et al. 2013). Interestingly, certain operational states of the microcircuit might require several elements of simultaneous inhibition. For example, UP to DOWN state transition in the cerebellar cortex is linked to the increase in the extracellular $\mathrm{K}^{+}$concentration (Wang et al. 2012), to local interneuronal activation (Oldfield et al. 2010), and to $\mathrm{GABA}_{\mathrm{B}}$ receptor activation (Mann et al. 2009; Craig et al. 2013). We propose that neurogliaform- processes shown in (b). d Distribution of the amplitude ( $\mathrm{dF} / \mathrm{F} 0)$, rise time, and half amplitude width of all calcium transients detected in astrocytes. e Mean fluorescence intensity, amplitude, and frequency of astrocytic calcium transients prior to and after activation of single NGFCs in a 1-s sliding window (black, average, gray, SD of all recordings). The green triangles denote NGFC activation

to-astrocyte interactions contribute to inhibitory scaling in the neocortex through multiple non-synaptic mechanisms.

Acknowledgments This work was supported by the ERC INTERIMPACT project and the Hungarian Academy of Sciences (G.T.).

\section{References}

Agnati LF, Leo G, Zanardi A et al (2006) Volume transmission and wiring transmission from cellular to molecular networks: history and perspectives. Acta Physiol 187:329-344. doi:10.1111/j. 1748-1716.2006.01579.x

Amzica F, Massimini M, Manfridi A (2002) Spatial buffering during slow and paroxysmal sleep oscillations in cortical networks of glial cells in vivo. J Neurosci 22:1042-1053

Ballanyi K, Grafe P, ten Bruggencate G (1987) Ion activities and potassium uptake mechanisms of glial cells in guinea-pig olfactory cortex slices. J Physiol 382:159-174

Barbour B, Häusser M (1997) Intersynaptic diffusion of neurotransmitter. Trends Neurosci 20:377-384. doi:10.1016/S01662236(96)20050-5

Bergles DE, Roberts JD, Somogyi P, Jahr CE (2000) Glutamatergic synapses on oligodendrocyte precursor cells in the hippocampus. Nature 405:187-191. doi:10.1038/35012083

Bushong EA, Martone ME, Ellisman MH (2004) Maturation of astrocyte morphology and the establishment of astrocyte domains during postnatal hippocampal development. Int J Dev Neurosci 22:73-86. doi:10.1016/j.ijdevneu.2003.12.008

Cahoy JD, Emery B, Kaushal A et al (2008) A transcriptome database for astrocytes, neurons, and oligodendrocytes: a new resource for 
understanding brain development and function. J Neurosci 28:264-278. doi:10.1523/JNEUROSCI.4178-07.2008

Capogna M (2011) Neurogliaform cells and other interneurons of stratum lacunosum-moleculare gate entorhinal-hippocampal dialogue. J Physiol 589:1875-1883. doi:10.1113/jphysiol.2010. 201004

Chittajallu R, Pelkey KA, McBain CJ (2013) Neurogliaform cells dynamically regulate somatosensory integration via synapsespecific modulation. Nat Neurosci 16:13-15. doi:10.1038/nn. 3284

Craig MT, McBain CJ (2014) The emerging role of GABAB receptors as regulators of network dynamics: fast actions from a "slow" receptor? Curr Opin Neurobiol 26:15-21. doi:10.1016/j. conb.2013.10.002

Craig MT, Mayne EW, Bettler B et al (2013) Distinct roles of GABAB1a- and GABAB1b-containing GABAB receptors in spontaneous and evoked termination of persistent cortical activity. J Physiol 591:835-843. doi:10.1113/jphysiol.2012. 248088

Di Castro MA, Chuquet J, Liaudet $\mathrm{N}$ et al (2011) Local $\mathrm{Ca}^{2+}$ detection and modulation of synaptic release by astrocytes. Nat Neurosci 14:1276-1284. doi:10.1038/nn.2929

Doengi M, Hirnet D, Coulon P et al (2009) GABA uptake-dependent $\mathrm{Ca}^{2+}$ signaling in developing olfactory bulb astrocytes. Proc Natl Acad Sci 106:17570-17575. doi:10.1073/pnas.0809513106

Dy JG, Brodley CE (2004) Feature selection for unsupervised learning. J Mach Learn Res 5:845-889

Egawa K, Yamada J, Furukawa T et al (2013) $\mathrm{Cl}^{-}$homeodynamics in gap junction-coupled astrocytic networks on activation of GABAergic synapses. J Physiol 591:3901-3917. doi:10.1113/ jphysiol.2013.257162

Eulenburg V, Gomeza J (2010) Neurotransmitter transporters expressed in glial cells as regulators of synapse function. Brain Res Rev 63:103-112. doi:10.1016/j.brainresrev.2010.01.003

Farrant M, Nusser Z (2005) Variations on an inhibitory theme: phasic and tonic activation of GABAA receptors. Nat Rev Neurosci 6:215-229. doi:10.1038/nrn1625

Freund TF, Buzsáki G (1996) Interneurons of the hippocampus. Hippocampus 6:347-470. doi:10.1002/(SICI)1098-1063(1996)6: 4<347:AID-HIPO1>3.0.CO;2-I

Fritschy J-M, Sidler C, Parpan F et al (2004) Independent maturation of the $\mathrm{GABA}(\mathrm{B})$ receptor subunits $\mathrm{GABA}(\mathrm{B} 1)$ and $\mathrm{GABA}(\mathrm{B} 2)$ during postnatal development in rodent brain. J Comp Neurol 477:235-252. doi:10.1002/cne.20188

Gentet LJ, Avermann M, Matyas F et al (2010) Membrane potential dynamics of GABAergic neurons in the barrel cortex of behaving mice. Neuron 65:422-435. doi:10.1016/j.neuron. 2010.01.006

Grosche J, Matyash V, Möller T et al (1999) Microdomains for neuron-glia interaction: parallel fiber signaling to Bergmann glial cells. Nat Neurosci 2:139-143. doi:10.1038/5692

Haustein MD, Kracun S, Lu X-H et al (2014) Conditions and constraints for astrocyte calcium signaling in the hippocampal mossy fiber pathway. Neuron 82:413-429. doi:10.1016/j.neuron. 2014.02.041

Hibino H, Inanobe A, Furutani K et al (2010) Inwardly rectifying potassium channels: their structure, function, and physiological roles. Physiol Rev 90:291-366. doi:10.1152/physrev.00021.2009

Kaila K, Lamsa K, Smirnov S et al (1997) Long-lasting GABAmediated depolarization evoked by high-frequency stimulation in pyramidal neurons of rat hippocampal slice is attributable to a network-driven, bicarbonate-dependent $\mathrm{K}^{+}$transient. J Neurosci 17:7662-7672

Kang J, Jiang L, Goldman SA, Nedergaard M (1998) Astrocytemediated potentiation of inhibitory synaptic transmission. Nat Neurosci 1:683-692. doi:10.1038/3684
Katona G, Szalay G, Maák P et al (2012) Fast two-photon in vivo imaging with three-dimensional random-access scanning in large tissue volumes. Nat Methods 9:201-208. doi:10.1038/nmeth. 1851

Kaupmann K, Huggel K, Heid J et al (1997) Expression cloning of GABA(B) receptors uncovers similarity to metabotropic glutamate receptors. Nature 386:239-246. doi:10.1038/386239a0

Kettenmann H, Backus KH, Schachner M (1984) Aspartate, glutamate and gamma-aminobutyric acid depolarize cultured astrocytes. Neurosci Lett 52:25-29. doi:10.1016/03043940(84)90345-8

Klausberger T, Somogyi P (2008) Neuronal diversity and temporal dynamics: the unity of hippocampal circuit operations. Science 321:53-57. doi:10.1126/science.1149381

Kofuji P, Newman EA (2004) Potassium buffering in the central nervous system. Neuroscience 129:1045-1056

Li Y, Dong M, Hua J (2008) Localized feature selection for clustering. Pattern Recognit Lett 29:10-18. doi:10.1016/j. patrec.2007.08.012

Lin S, Bergles DE (2004) Synaptic signaling between GABAergic interneurons and oligodendrocyte precursor cells in the hippocampus. Nat Neurosci 7:24-32. doi:10.1038/nn1162

López-Bendito G, Shigemoto R, Kulik A et al (2004) Distribution of metabotropic GABA receptor subunits GABAB1a/b and GABAB2 in the rat hippocampus during prenatal and postnatal development. Hippocampus 14:836-848. doi:10.1002/hipo. 10221

Losi G, Mariotti L, Carmignoto G (2014) GABAergic interneuron to astrocyte signalling: a neglected form of cell communication in the brain. Philos Trans R Soc B Biol Sci 369:20130609. doi:10. 1098/rstb.2013.0609

Luján R, Shigemoto R (2006) Localization of metabotropic GABA receptor subunits $\mathrm{GABAB} 1$ and $\mathrm{GABAB} 2$ relative to synaptic sites in the rat developing cerebellum. Eur $\mathrm{J}$ Neurosci 23:1479-1490. doi:10.1111/j.1460-9568.2006.04669.x

Ma B-F, Xie M-J, Zhou M (2012) Bicarbonate efflux via GABAA receptors depolarizes membrane potential and inhibits two-pore domain potassium channels of astrocytes in rat hippocampal slices. Glia 60:1761-1772. doi:10.1002/glia.22395

Ma B, Xu G, Wang W et al (2014) Dual patch voltage clamp study of low membrane resistance astrocytes in situ. Mol Brain 7:18. doi:10.1186/1756-6606-7-18

Mann EO, Kohl MM, Paulsen O (2009) Distinct roles of GABAA and $\mathrm{GABAB}$ receptors in balancing and terminating persistent cortical activity. J Neurosci 29:7513-7518. doi:10.1523/JNEUR OSCI.6162-08.2009

Markram H, Toledo-Rodriguez M, Wang Y et al (2004) Interneurons of the neocortical inhibitory system. Nat Rev Neurosci 5:793-807. doi:10.1038/nrn1519

Martin SC, Steiger JL, Gravielle MC et al (2004) Differential expression of gamma-aminobutyric acid type B receptor subunit mRNAs in the developing nervous system and receptor coupling to adenylyl cyclase in embryonic neurons. J Comp Neurol 473:16-29. doi:10.1002/cne.20094

McLachlan GJ, Peel DA (2000) Finite mixture models. Wiley, New York

Meier SD, Kafitz KW, Rose CR (2008) Developmental profile and mechanisms of GABA-induced calcium signaling in hippocampal astrocytes. Glia 56:1127-1137. doi:10.1002/glia.20684

Miles R, Wong RK (1984) Unitary inhibitory synaptic potentials in the guinea-pig hippocampus in vitro. J Physiol 356:97-113

Mishima T, Hirase H (2010) In vivo intracellular recording suggests that gray matter astrocytes in mature cerebral cortex and hippocampus are electrophysiologically homogeneous. J Neurosci 30:3093-3100. doi:10.1523/JNEUROSCI.5065-09.2010 
Nilsson M, Eriksson PS, Rönnbäck L, Hansson E (1993) GABA induces $\mathrm{Ca}^{2+}$ transients in astrocytes. Neuroscience 54:605-614. doi:10.1016/0306-4522(93)90232-5

Oláh S, Füle M, Komlósi G et al (2009) Regulation of cortical microcircuits by unitary GABA-mediated volume transmission. Nature 461:1278-1281. doi:10.1038/nature08503

Oldfield CS, Marty A, Stell BM (2010) Interneurons of the cerebellar cortex toggle Purkinje cells between up and down states. Proc Natl Acad Sci 107:13153-13158. doi:10.1073/pnas.1002082107

Otis TS, Staley KJ, Mody I (1991) Perpetual inhibitory activity in mammalian brain slices generated by spontaneous GABA release. Brain Res 545:142-150

Porter JT, McCarthy KD (1997) Astrocytic neurotransmitter receptors in situ and in vivo. Prog Neurobiol 51:439-455. doi:10.1016/ S0301-0082(96)00068-8

Pouille F, Scanziani M (2004) Routing of spike series by dynamic circuits in the hippocampus. Nature 429:717-723. doi:10.1038/ nature 02615

Serrano A (2006) GABAergic network activation of glial cells underlies hippocampal heterosynaptic depression. J Neurosci 26:5370-5382. doi:10.1523/JNEUROSCI.5255-05.2006

Simon A, Oláh S, Molnár G et al (2005) Gap-junctional coupling between neurogliaform cells and various interneuron types in the neocortex. J Neurosci 25:6278-6285. doi:10.1523/JNEUROSCI. 1431-05.2005

Sun W, McConnell E, Pare J-F et al (2013) Glutamate-dependent neuroglial calcium signaling differs between young and adult brain. Science 339(80):197-200. doi:10.1126/science. 1226740

Tamas G (2003) Identified sources and targets of slow inhibition in the neocortex. Science 299(80):1902-1905. doi:10.1126/science. 1082053
Thomson AM, Bannister AP, Mercer A, Morris OT (2002) Target and temporal pattern selection at neocortical synapses. Philos Trans R Soc B Biol Sci 357:1781-1791. doi:10.1098/rstb.2002.1163

Velez-Fort M, Audinat E, Angulo MC (2012) Central role of GABA in Neuron-Glia Interactions. Neurosci 18:237-250. doi:10.1177/ 1073858411403317

Viitanen T, Ruusuvuori E, Kaila K, Voipio J (2010) The $\mathrm{K}^{+}-\mathrm{Cl}$ cotransporter $\mathrm{KCC} 2$ promotes GABAergic excitation in the mature rat hippocampus. J Physiol 588:1527-1540. doi:10.1113/ jphysiol.2009.181826

Vizi ES, Kiss JP (1998) Neurochemistry and pharmacology of the major hippocampal transmitter systems: synaptic and nonsynaptic interactions. Hippocampus 8:566-607. doi:10.1002/ (SICI) 1098-1063(1998)8:6<566:AID-HIPO2>3.0.CO;2-W

Vizi ES, Kiss JP, Lendvai B (2004) Nonsynaptic communication in the central nervous system. Neurochem Int 45:443-451. doi:10. 1016/j.neuint.2003.11.016

Volterra A, Liaudet N, Savtchouk I (2014) Astrocyte $\mathrm{Ca}^{2+}$ signalling: an unexpected complexity. Nat Rev Neurosci 15:327-335. doi: $10.1038 / n$ rn 3725

Wang F, Xu Q, Wang W et al (2012) Bergmann glia modulate cerebellar Purkinje cell bistability via $\mathrm{Ca}^{2+}$-dependent $\mathrm{K}^{+}$ uptake. Proc Natl Acad Sci 109:7911-7916. doi:10.1073/pnas. 1120380109

Williams SR, Mitchell SJ (2008) Direct measurement of somatic voltage clamp errors in central neurons. Nat Neurosci 11:790-798. doi:10.1038/nn.2137

Zhou M (2005) Development of GLAST(+) astrocytes and NG2(+) glia in rat hippocampus CA1: mature astrocytes are electrophysiologically passive. J Neurophysiol 95:134-143. doi:10. 1152/jn.00570.2005 